\title{
Improved planting managements may increase vegetation carbon sequestration of an artificial grassland on the Qinghai-Tibetan Plateau
}

\author{
Fuquan $\mathrm{He}^{1}$, Qi $\mathrm{Li}^{1}$, Dongdong Chen ${ }^{1}$, Xinquan Zhao ${ }^{2}$, Xin Chen ${ }^{1}$, and Liang Zhao ${ }^{3}$ \\ ${ }^{1}$ Northwest Institute of Plateau Biology, Chinese Academy of Sciences, Xining, China \\ ${ }^{2}$ Northwest Institute of Plateau Biology, Chinese Academy of Sciences \\ ${ }^{3}$ Northwest Institute of Plateau Biology Chinese Academy of Sciences
}

April 28, 2020

\begin{abstract}
The cultivation of artificial grassland, which requires regular sowing and harvesting, is an important and common practice in grassland management and restoration on the Qinghai-Tibetan Plateau (QTP). However, the key factors and successional processes that determine its interannual variability of net ecosystem exchange (NEE) remains unclear. In this study, we analyzed 6 years of eddy covariance observations, quantified seasonal and annual NEE, net carbon uptake period length (CUP), two largest carbon emission periods length (CEPs), and daily minimum and maximum NEE (NEEmin, NEEmax) responses to management measures in an alley silvopasture system with planted Elymus nutans on the QTP. We examined NEE variations before and after sowing and harvesting and investigated how sowing and harvesting managements affect NEE. The five-year life cycle study revealed that this artificial perennial grassland was a weak net carbon sink with an uptake of $-180 \mathrm{~g} \mathrm{C} \mathrm{m}^{-2}$ per plant cycle (2012-2016). Inter-annual variations in NEE was determined by CUP and the first largest carbon emission periods (CEP1). Sowing delayed the beginning of CUP (BCUP) by about 42 days and caused spring $\mathrm{C}$ uptake to decline by $-36 \mathrm{~g} \mathrm{C} \mathrm{m}^{-2}$. In contrast, harvesting caused the ending of CUP (ECUP) to advance about 25 days, and caused a decease of autumn $\mathrm{C}$ uptake about $-33 \mathrm{~g} \mathrm{C} \mathrm{m}^{-2}$. Sowing and harvesting shortened the CUP and extended the CEP1, which reduces the carbon sequestration potential of the artificial grassland. Based on our results, we recommend that policy makers and authorities consider the effect of timing of sowing and harvesting on $\mathrm{C}$ sequestration. Our results provide a new insight for grassland management and the inter-annual variability of NEE on climate mitigation and regional sustainability.
\end{abstract}

\section{Hosted file}

Manuscript.doc available at https : //authorea.com/users/309701/articles/440566-improved-plantingmanagements-may-increase-vegetation-carbon-sequestration-of-an-artificial-grassland-on-theqinghai-tibetan-plateau

\section{Hosted file}

Figures andTables .doc available at https://authorea.com/users/309701/articles/440566-improvedplanting-managements-may-increase-vegetation-carbon-sequestration-of-an-artificial-grasslandon-the-qinghai-tibetan-plateau 